\title{
Association of mean platelet volume and platelet distribution width with diabetic retinopathy in patients with diabetes mellitus
}

\author{
Shubhratha S. Hegde ${ }^{1, *}$, Mahima S.R ${ }^{2}$, Sandhya Dharwadkar ${ }^{3}$, Mohammad Abdul Kayoom N ${ }^{4}$, \\ Shashidhar H. B
}

${ }^{1}$ Assistant Professor, ${ }^{2}$ Post Graduate, ${ }^{3}$ Senior Resident, ${ }^{4}$ Post Graduate, ${ }^{5}$ Professor, ${ }^{1,2,3,4}$ Dept. of Ophthalmology, ${ }^{5}$ Dept. of Pathology, Mysore Medical College \& Research Institute, Mysore, Karnataka, India

*Corresponding Author: Shubhratha S. Hegde

Email: drshubhratha@gmail.com

\begin{abstract}
Introduction: MPV and PDW are indicators of subclinical platelet hyperactivity and can be used as predictive factors for development and progression of diabetic retinopathy.

Materials and Methods: This prospective case control study enrolled 150 patients with diabetic retinopathy (DR group) and 150 diabetic patients without retinopathy (control group). Detailed history and ophthalmic examination was done. The DR group was divided into 5 subgroups according to the ETDRS classification of diabetic retinopathy. MPV, PDW, FBS and PPBS values were obtained.

Result: The mean value of MPV in DR group was higher compared to control group $(p=0.016)$. PDW also followed the similar trend with DR group having mean value of $13.71 \pm 1.36 \mathrm{fl}$ and control group having $12.13 \pm 1.29 \mathrm{fl}$ ( $p=0.023$ ). The study also found a trend of increase in severity of diabetic retinopathy with increasing level of MPV and PDW. However a statistically significant association was found only between MPV and stage of diabetic retinopathy $(\mathrm{r}=0.214, p=0.046)$. A marked increase in MPV and PDW values were found in those with Proliferative diabetic retinopathy $(p<0.001)$. A significant correlation was found between MPV and PDW and poor glycemic control. No correlation was found between MPV and PDW and duration of diabetes.
\end{abstract}

Conclusion: Platelet indices like MPV can be a cheap and easy to measure tool for monitoring diabetic retinopathy.

Keywords: Mean platelet volume, Platelet distribution width, Diabetic retinopathy, Proliferative diabetic retinopathy.

\section{Introduction}

Diabetes mellitus is an important public health problem worldwide. ${ }^{1,2}$ WHO has estimated that there are 171 million people worldwide with diabetes and predicted that 366 million will have diabetes by $2030 .^{1,3,4}$ In India, the number of people affected by diabetes is estimated to rise to 79.4 million by 2030 , the largest number in any nation in the world. ${ }^{5,6}$ Diabetic retinopathy (DR) is a very common, potentially preventable, long-term, microvascular complication of diabetes mellitus and a leading cause of visual disability and blindness. ${ }^{7}$ WHO has estimated that diabetic retinopathy is responsible for $4.8 \%$ of the 37 million cases of blindness in the world. ${ }^{1,8}$

Diabetes mellitus (DM) has been considered as a 'prothrombotic state' with increased platelet activity. ${ }^{9-13}$ However, it is not clear whether the platelet abnormalities seen in diabetes are intrinsic to the platelet or are a consequence of circulating factors that affect platelet function. ${ }^{14}$ Insulin is a natural antagonist of platelet hyperactivity. It sensitizes platelets to the inhibitory actions of prostacyclin and NO on aggregation and reduces the pro- aggregatory properties of a number of agonists - PGE1, PGE2, ADP, collagen, thrombin etc. In diabetics there is loss of sensitivity to the normal restraints exercised by prostacyclin (PGI2) and nitric oxide (NO) and increased sensitivity to proaggregatory agents thereby causing rapid platelet aggregation and adherence to vascular endothelium..$^{14,15}$ Exaggerated intracellular calcium, suppressed intracellular magnesium and increased thromboxane levels present in diabetes may also lead to enhanced platelet aggregation. ${ }^{2,16}$ The endothelium may also contribute to platelet activation in diabetes by releasing von Willebrand factor, a GP constituent of the factor VIII complex, which promotes platelet clumping by binding to the platelet. $^{14}$ Hyperglycemia can increase platelet reactivity by inducing nonenzymatic glycation of surface proteins on the platelet, by the osmotic effect of glucose and activation of protein kinase. ${ }^{2,16,17}$

MPV and PDW are easy to quantify and inexpensive tests, measured as a part of complete blood count which can identify platelet hyperactivity. $7,13,18-20$ MPV is an indicator of the average size and activity of platelets. ${ }^{4,7}$ The function of platelets seems to be related to their sizes. Larger platelets are younger, more reactive, contain more dense granules and produce large amounts of thromboxane A2 and hence exhibit hyperresponsiveness to ADP- or collagen-induced aggregation when compared with smaller and less active platelets. $2,4,5,7,11,13,15,17,20-24$ Platelet distribution width (PDW) is an indicator of variation in platelet size. It is also a marker of platelet activity. ${ }^{7,25} \mathrm{PDW}$ is a more specific marker of platelet activation as it does not increase during simple platelet swelling. ${ }^{18,19}$ Platelet activation causes morphologic changes like spherical shape and pseudopodia formation. Platelets with increased number and size of pseudopodia, differ 
in size and affect platelet distribution width (PDW). ${ }^{9,19}$ Therefor higher MPV and PDW means more platelet activity and greater platelet turnover.

High MPV is emerging as a new risk factor for microvascular complications of DM. ${ }^{17}$ Higher values of MPV are seen in diabetic patients with microvascular complications like retinopathy. ${ }^{15}$ The purpose of this study is to compare MPV and PDW values in diabetic with and without retinopathy and to find their association with various degrees of diabetic retinopathy.

\section{Materials and Methods}

In this prospective case control study, 150 patients with diabetic retinopathy (DR group) and 150 diabetes patients without diabetic retinopathy changes (control group) were included after obtaining consent. Patients with anemia and/or thrombocytopenia, patients on antiplatelet medications, pregnant were excluded as they cause increased MPV and PDW. Patients who have undergone LASER treatment for diabetic retinopathy and patients in whom fundus examination is not possible due to dense cataract or rigid pupil were also excluded from the study as staging of retinopathy is not possible.

Detailed history was taken. Complete ophthalmic evaluation of all patients was done. Dilated fundus examination was done using slit lamp biomicroscopy with 78D lens and indirect ophthalmoscopy. Fundus flourescien angiography and optical coherence tomography was done whenever required. In patients with diabetic retinopathy clinical staging of retinopathy was done as per ETDRS classification.

Blood samples were collected from the patients in EDTA and fluoride vacutainers for measurement of complete blood count and blood sugar levels in automated analyzers. Intra- and intergroup comparisons of MPV, PDW, FBS and PPBS values were performed.

Statistical analysis was performed by Statistical Package for the Social Sciences (SPSS) version 15 for windows using student $t$ test and pearson correlation test ( $\mathrm{r}$ value as the coefficient). The data was expressed as mean \pm standard deviation. Mean values of DR group and control group were compared by student $t$ test. For subgroup analysis, one way ANOVA test was used. A $p$ value $<0.05$ was considered statistically significant.

\section{Results}

There were 166 male diabetics and 89 female diabe tics in the DR group and 100 male diabetics and 50 females in control group. The mean age of the DR group and control group were $61.45 \pm 6.32$ years and $57.95 \pm 6.17$ years respectively. There was no statistically significant difference between the 2 groups with respect to the age $(p=0.67)$. The duration since diagnosis of diabetes ranged from 1-25 years. The mean duration in DR group and control group was $9.05 \pm$ 4.45 years and $6.27 \pm 1.24$ years respectively. $74 \%$ of the patients in DR group and $79.33 \%$ of the patients in control group were on oral hypoglycemic agents. (Table 1)

DR group included 64 mild NPDR, 45 moderate NPDR, 16 severe NPDR, 11 very severe NPDR and 14 PDR cases.

Most of the subjects in DR group had uncontrolled diabetes suggested by elevated FBS and PPBS levels. Mean FBS level and PPBS levels were higher in DR group as compared to control group. (Table 2)

The mean value of MPV in DR group and control group were $8.89 \pm 0.73 \mathrm{fl}$ and $8.04 \pm 0.78 \mathrm{fl}$ respectively. The mean value of MPV was higher in DR group as compared to control group ( $\mathrm{p}=0.016)$. PDW also followed the similar trend with DR group having mean value of $13.71 \pm 1.36 \mathrm{fl}$ and control group having 12.13 $\pm 1.29 \mathrm{fl}(\mathrm{p}=0.023)$. However, both parameters in diabetics on treatment were within normal reference ranges of healthy individuals. (Table 3 )

All the stages of diabetic retinopathy had higher mean values of MPV compared to the control group (Table 4). A significant correlation was found between the degree of retinopathy and MPV ( $r=0.214$, $\mathrm{p}=0.046$ ). PDW values were also significantly higher in all stages of retinopathy compared to the control group (Table 5). No significant correlation was found between degree of retinopathy and PDW $(r=-0.032)(\mathrm{p}=0.51)$

In the DR group, a positive statistical correlation was found between MPV and $\operatorname{FBS}(r=0.357 ; p$ $=<0.001)$ between MPV and PPBS levels $(r=0.294 ; p$ $=0.003)$. A significant correlation was also found between PDW and FBS $(r=0.232 ; p=0.004)$. However, no statistical correlation was seen between PDW and PPBS. No correlation was found between MPV and PDW and the duration of DM. (Table 6)

\section{Discussion}

We studied whether the values of MPV and PDW are different in diabetic patients with retinopathy as compared to diabetic patients without retinopathy. We found higher MPV and PDW values in diabetics with retinopathy. Jindal et al, ${ }^{10}$ Buch et al, ${ }^{11}$ Alhadas et al, ${ }^{22}$ Yilmaz et al, ${ }^{25}$ also found that both MPV and PDW were associated with DR. Kodiatte et al, ${ }^{4}$ Rajesh kanna, ${ }^{5}$ Tetikoğlu et al, ${ }^{7}$ Citirik et al, ${ }^{9}$ Gungor et al, ${ }^{28}$ Ates, et al, ${ }^{15}$ Dindar et $a{ }^{2},{ }^{26}$ Papanas et al ${ }^{27}$ Tuzcu et $\mathrm{al}^{29}{ }^{29}$ Hekimsoy et $\mathrm{al}^{30}$ Madhavan et $\mathrm{al},{ }^{31}$ found significant correlation between MPV and DR. By contrast, Aydinli et $\mathrm{al}^{32}$ and Demirtunc et $\mathrm{al}^{33}$ advocated that there was no association between MPV and DR. Citirik et $\mathrm{al}^{9}{ }^{9}$ Tetikoğlu et $\mathrm{al}^{7}$ found no significant correlation between PDW and DR.

The present study showed a trend of increasing levels of MPV and PDW with the increase in the severity of diabetic retinopathy. Mean MPV and PDW values in all stages of retinopathy were significantly higher compared to control group. A positive correlation was present between the degree of 
retinopathy and values of MPV. However no correlation was found between PDW and degree of retinopathy. Yilmaz et $\mathrm{al}^{25}$ found an association between mean platelet indices (i.e., MPV, PDW, and PLCR)and DR stage. Ates et $\mathrm{al}^{15}$ found an increase in MPV with the stage of retinopathy. But Kodiette et al, ${ }^{4}$ Citirik et al, ${ }^{9}$ Gungor et $\mathrm{al}^{28}$ found no correlation between MPV values and stages of retinopathy. Similar to our study Tetikoğlu et $\mathrm{al}^{7}$ and Citirik et $\mathrm{al}^{9}$ also found no association between PDW and stages of retinopathy.

The increase in MPV and PDW values were more apparent in advanced stages of retinopathy. We found marked increase in MPV and PDW values, particularly in those with proliferative retinopathy, which suggests a role of increased platelet activity in the pathogenesis of proliferative retinopathy. Yilmaz et $\mathrm{al}^{25}$ stated that MPV and PDW values were a significantly higher in patients who developed PDR suggesting the role of platelets in development of retinal neovascularisation. Tetikoğlu et al, ${ }^{7}$ Tuzcu et al, ${ }^{29}$ Zhong et $\mathrm{al}^{34}$ found that MPV was significantly higher in patients with PDR.
Our study suggests that increased MPV is associated with poor glycemic control. This coincides with the results of Kodiatte et al, ${ }^{4}$ Rajesh Kanna, ${ }^{5}$ Jindal et al, ${ }^{10}$ Buch et al, ${ }^{11}$ Hasan et al, ${ }^{17}$ Zaccardi et al, ${ }^{18}$ Vernekar et al, ${ }^{19}$ Shah b et al, ${ }^{20}$ Zuberi et al, ${ }^{21}$ Ozder et al, ${ }^{24}$ Dindar et al, ${ }^{26}$ Papanas et al, ${ }^{27}$ Gungor et al, ${ }^{28}$ Hekimsoy et $\mathrm{al}^{30}$ Demirtunc et $\mathrm{al}^{33}$ and Coban et al ${ }^{35}$ but contradicts the results of Dayal et al, ${ }^{2}$ Cakir et al, ${ }^{31}$ Unübol et $\mathrm{al}^{36}$ and Alhadas et $\mathrm{al}^{22}$ found a positive correlation between both MPV and PDW and blood glucose levels.

In our study no correlation was found between MPV and PDW, and duration of diabetes similar to Papanas et al, ${ }^{27}$ Madhavan et al, ${ }^{23}$ Cakir et $\mathrm{al}^{31}$ and Hasan et al. ${ }^{37}$ However Kodiette et al, ${ }^{4}$ Akinsegun et $\mathrm{al}^{13}$ and Gungor et $\mathrm{al}^{28}$ found significant correlation between MPV and duration of diabetes.

A limitation of this study was its relatively small sample size. Another limitation was that confounding factors like smoking were not taken into account.

Table 1: Age, duration of diabetes and treatment

\begin{tabular}{|c|c|c|c|}
\hline \multicolumn{2}{|c|}{ 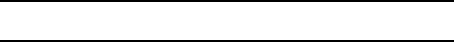 } & DR Group & Control Group \\
\hline \multicolumn{2}{|c|}{ Age (years) } & $61.45 \pm 6.99$ & $57.96 \pm 6.07$ \\
\hline \multicolumn{2}{|c|}{ Duration of diabetes (years) } & $9.04 \pm 4.65$ & $6.24 \pm 1.29$ \\
\hline \multirow{2}{*}{$\begin{array}{l}\text { Treatment } \\
\text { modality }\end{array}$} & $\mathrm{OH}$ & $79 \%$ & $74 \%$ \\
\hline & Insulin & $21 \%$ & $26 \%$ \\
\hline
\end{tabular}

Table 2: Mean values of in the blood sugar levels in 2 groups

\begin{tabular}{|l|c|c|}
\hline & DR Group & Control Group \\
\hline FBS (mg/dl) & $133.73 \pm 56.41$ & $104.57 \pm 35.33$ \\
\hline PPBS (mg/dl) & $217.6 \pm 87.86$ & $179.75 \pm 20.49$ \\
\hline
\end{tabular}

Table 3: Comparision of MPV and PDW between 2 groups

\begin{tabular}{|l|c|c|c|}
\hline & DR group & Control group & p value \\
\hline MPV(fl) & $8.89 \pm 0.73$ & $8.04 \pm 0.78$ & 0.016 \\
\hline PDW(fl) & $13.71 \pm 1.36$ & $12.13 \pm 1.29$ & 0.023 \\
\hline
\end{tabular}

Table 4: MPV values in different stages of diabetic retinopathy

\begin{tabular}{|l|c|c|c|c|c|}
\hline & Mild NPDR & $\begin{array}{c}\text { Moderate } \\
\text { NPDR }\end{array}$ & Severe NPDR & $\begin{array}{c}\text { Very severe } \\
\text { NPDR }\end{array}$ & PDR \\
\hline MPV (fl) & $8.25 \pm 0.68$ & $8.48 \pm 0.74$ & $8.62 \pm 0.67$ & $8.74 \pm 0.78$ & $9.92 \pm 0.69$ \\
\hline $\begin{array}{l}\text { p value (on comparision } \\
\text { with control group) }\end{array}$ & 0.024 & 0.037 & 0.016 & 0.007 & $<0.001$ \\
\hline
\end{tabular}

Table 5: PDW values in different stages of diabetic retinopathy.

\begin{tabular}{|l|c|c|c|c|c|}
\hline & Mild NPDR & Mod. NPDR & sev. NPDR & v.sev. NPDR & PDR \\
\hline PDW & $13.02 \pm 1.26$ & $13.24 \pm 1.14$ & $13.42 \pm 1.37$ & $13.48 \pm 1.26$ & $13.77 \pm 1.36$ \\
\hline $\begin{array}{l}\text { p value (on comparision with } \\
\text { control group) }\end{array}$ & 0.048 & 0.028 & 0.013 & 0.003 & $<0.001$ \\
\hline
\end{tabular}

Table 6: Comparision of MPV and PDW to various parameters

\begin{tabular}{|l|c|c|c|c|}
\hline \multicolumn{1}{|c|}{ Parameter } & \multicolumn{2}{c|}{ MPV } & \multicolumn{2}{c|}{ PDW } \\
\hline & r value & $\mathrm{p}$ value & r value & $\mathrm{p}$ value \\
\hline Duration of diabetes & -0.93 & 0.858 & -0.32 & 0.162 \\
\hline FBS & 0.357 & $<0.001$ & 0.232 & 0.004 \\
\hline PPBS & 0.294 & 0.003 & 0.193 & 0.008 \\
\hline
\end{tabular}




\section{Conclusion}

We found an association between MPV and PDW and diabetic retinopathy. Moreover, an increase in MPV values was observed with increasing severity of DR. This finding suggests a role of platelets in the pathogenesis of diabetic retinopathy and that mean platelet volume would be useful in monitoring the disease progression. MPV can emerge as an important, simple, effortless, and cost-effective tool for monitoring and for early recognition of microvascular complications in Diabetes Mellitus.

\section{References}

1. WHO. Prevention of blindness from diabetes mellitus. 2006. Available from:

http:/ww.who.int/diabetes/publications/prevention_diabet es2006/en/

2. Dayal A, Kothari S, Shah RJ, Patel SM. Mean Platelet

Volume In Diabetes Mellitus Type II. Annals of

Pathology and Laboratory Medicine. 2016;3(6):567-572.

3. Global Prevalence of Diabetes. Estimates for the year 2000 and projections for 2030. Wild S, Roglic G, Green A, Sicree R, King H. Diabetes Care. 2004;27(5):10471053.

4. Kodiatte TA, Manikyam UK, Rao SB, Jagadish TM, Reddy M, Lingaiah HK, Lakshmaiah V. Mean Platelet Volume in Type 2 Diabetes Mellitus. J Lab Physicians. 2012;4(1):5-9.

5. Radha RKN, Selvam D. MPV, an Indicator of Vascular Complication in Type 2 DM. J of Clinical and Diagnostic Research. 2016;10(8):22-26.

6. Gadkari SS, Maskati QB, Nayak BK. Prevalence of diabetic retinopathy in India: The All India Ophthalmological

Society Diabetic Retinopathy Eye Screening Study 2014. Ind J Ophthalmol. 2016;64(1):38-44.

7. Tetikoğlu M, Aktas S, Sagdık HM, Yigitoglu ST, Özcura F: Mean Platelet Volume is Associated with Diabetic Macular Edema in Patients with Type-2 Diabetes Mellitus, Seminars in Ophthalmology. 2016; DOI: 10.3109/08820538.2016.1157612.

8. Resnikoff S, Pascolini D, Etya'ale D, Kocur I, Pararajasegaram R, Pokharel GP et al. Global data on visual impairment in the year 2002. Bulletin of the World Health Organization. 2004;82(11):844-851.

9. Citirik M, Beyazyildiz E, Sımsek M, Beyazyildiz O, Haznedaroğlu IC. MPV may reflect subclinical platelet activation in diabetic patients with and without diabetic retinopathy. Eye (Lond). 2015;29(3):376-379.

10. Jindal S, Gupta S, Gupta R, Kakkar A, Singh HV, Gupta $\mathrm{K}$ et al. Platelet indices in diabetes mellitus: Indicators of diabetic microvascular complications. Hematology. 2011;16(2):86-89.

11. Buch A, Kaur S, Nair R, Jain A. Platelet volume indices as predictive biomarkers for diabetic complications in Type 2 diabetic patients. J Lab Physicians. 2017;9(2):848.

12. Bae SH, Lee J, Roh KH, Kim J. Platelet activation in patients with diabetic retinopathy. Korean J Ophthalmol. 2003; 17:140-144.

13. Akinsegun A, Olusola AD, Sarah JO, Olajumoke $\mathrm{O}$, Adewumi A, Majeed $\mathrm{O}$ et al. Mean platelet volume and platelet counts in type 2 diabetes: mellitus on treatment and non-diabetic mellitus controls in Lagos, Nigeria. Pan Afr Med J. 2014;18(42) doi: 10.11604/pamj.2014.18.42.3.
14. Vinik AI, Erbas T, Park TS, Nolan R, Nolan R, Platelet Dysfunction in Type 2 Diabetes. Diabetes Care. 2001;24(8):1476-1485.

15. Ates O, Kiki I, Bilen H, Keles M, Koçer I, Kulaçoglu DN. Association of Mean Platelet Volume With The Degree of Retinopathy in Patients with Diabetes Mellitus. Eur J Gen Med. 2009;6(2):99-102.

16. Cai J, Boulton M. The pathogenesis of diabetic retinopathy: old concepts and new questions. Eye. 2002;16:242-260.

17. Hasan Z, Hegde S, Uday I, Jayakumar NM, Anantharajaiah PH. Assessment of Mean Platelet Volume in Type 2 Diabetes Mellitus and Prediabetes. National $J$ of Laboratory Medicine. 2016;5(3):54-57.

18. Zaccardi F, Rocca B, Pitocco D, Tanese L, Rizzi A, Ghirlanda G. Platelet mean volume, distribution width, and count in type 2 diabetes, impaired fasting glucose, and metabolic syndrome: A meta-analysis. Diabetes Metab Res Rev. 2015;31(4):402-410.

19. Vernekar PV, Vaidya K. Comparison of Mean Platelet Volume in Type 2 Diabetics on Insulin Therapy and on oral hypoglycemic agents. J Clin Diagn Res. 2013;7(12):2839-2840

20. Shah B, Sha D, Xie D, Mohler ER III, Berger JS. The relationship between diabetes, metabolic syndrome, and platelet activity as measured by mean platelet volume: The National Health and Nutrition Examination Survey, 1999-2004. Diabetes Care. 2012;35:1074-1078.

21. Zuberi B F, Akhtar N, Afsar S. Comparison of mean platelet volume in patients [11] with diabetes mellitus, impaired fasting glucose and non-diabetic subjects. Singapore Med J. 2008;49(2):114-16.

22. Alhadas KR, Santos SN, S. Freitas MM, Viana SMAA, Ribeiro LC, Mônica B. Costa MB. Are platelet indices useful in the evaluation of type 2 diabetic patients? Bras Patol Med Lab. 2016;52(2):96-102.

23. Madhavan K, Priyadarshini V, Sivaprakash V, Kumaran B. Study on Mean Platelet Volume in Type 2 Diabetes Mellitus Patients vs Non Diabetic Patients. JMSCR. 2017;05(03):18573-18577.

24. Ozder A, Eker HH. Investigation of mean platelet volume in patients with type 2 diabetes mellitus and in subjects with impaired fasting glucose: a cost-effective tool in primary health care. Int J Clin Exp Med. 2014;7(8):22922297.

25. Yilmaz T, Yilmaz A. Relationship between Altered Platelet Morphological Parameters and Retinopathy in Patients with Type 2 Diabetes Mellitus. J Ophthalmol. 2016. doi: 10.1155/2016/9213623

26. Dindar S, Cinemre H, Sengul E, Annakkaya AN. Mean platelet volume is associated with glycaemic control and retinopathy in patients with Type 2 Diabetes Mellitus. West Indian Med J. 2013;62(6):519-23.

27. Papanas N, Symeonidis G, Maltezos E, Mavridis G, Karavageli E, Vosnakidis T et al. Mean platelet volume in patients with type 2 diabetes mellitus. Platelets. 2004;15(8):475-78.

28. Güngör AA, Gürsoy G, Güngör F, Bayram SM, Atalay E. The relationship of mean platelet volume with retinopathy in type 2 diabetes mellitus. Turk J Med Sci. 2016;46(5):1292-1299.

29. Tuzcu AE, Arıca S, Ilhan N, Daglioglu M, Coskun M, Ilhan O. Relationship between mean platelet volume and retinopathy in patients with type 2 diabetes mellitus. Graefes Arch Clin Exp Ophthalmol. 2014;252:237-240.

30. Hekimsoy Z, Payzin B, Ornek T, Kandogan G. Mean platelet volume in Type 2 Diabetic patients. J Diabetes Complications. 2004;18(3):173-176. 
31. Cakir L, Aktas G, Enginyurt O, Cakir SA. Mean Platelet volume increases in type 2 diabetes mellitus independent of HbA1c level. Acta Medica Mediterranea 2014;30:425428.

32. Aydinli S, Saydam G, Sahin F, Tuzun M, Buyukkececi F. The relationship between mean platelet volume, invitro platelet function tests and microvascular complications in type 2 diabetes mellitus. Turkish Hematology and Oncology Journal. 2004;14:193-199.

33. Demirtunc R, Duman D, Basar M, Bilgi M, Teomete M, Garip T. The relationship between glycaemic control and platelet activity in type 2 diabetes mellitus. J Diabetes Complications. 2009;23:89-94.

34. Zhong ZL, Han M, Chen S. Risk factors associated with retinal neovascularization of diabetic retinopathy in type 2 diabetes mellitus. Int J Ophthalmol. 2011;4(2):182-5.

35. Coban E, Bostan F, Ozdogan M. The mean platelet volume in subjects with impaired fasting glucose. Platelets. 2006;17(1):67-69.
36. Ünübol M, Ayhan M, Güney E. The relationship between mean platelet volume with microalbuminuria and glycaemic control in patients with type II diabetes mellitus. Platelets. 2012;23(6):475-480.

How to cite this article: Hegde S. S, Mahima S.R, Dharwadkar S, Mohammad A.K.N, Shashidhar H.B. Association of mean platelet volume and platelet distribution width with diabetic retinopathy in patients with diabetes mellitus. Indian J Clin Exp Ophthalmol. 2018;4(4):530-534. 